\title{
DEVELOPMENT OF AN AGING INTEGRATOR FOR URANIUM-0.75 WEIGHT PERCENT TITANIUM ALLOY PART AGING CONTROL
}

L. C. Howington

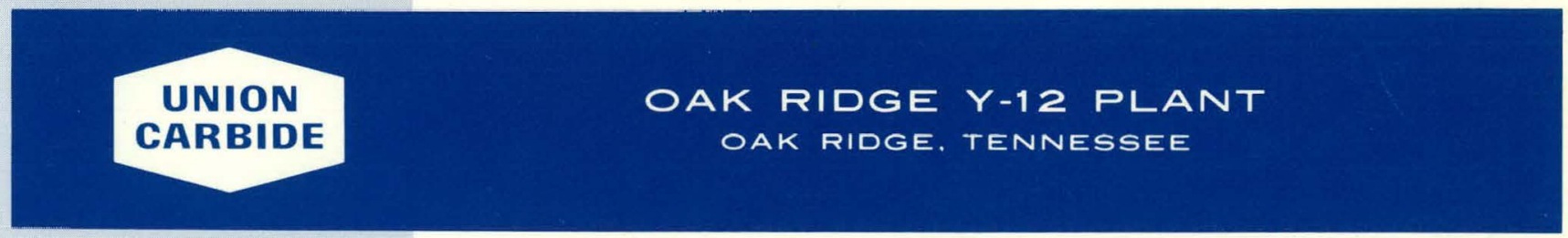

prepared for the U.S. DEPARTMENT OF ENERGY under U.S. GOVERNMENT Con tract W-7405 eng 26 


\section{DISCLAIMER}

This report was prepared as an account of work sponsored by an agency of the United States Government. Neither the United States Government nor any agency Thereof, nor any of their employees, makes any warranty, express or implied, or assumes any legal liability or responsibility for the accuracy, completeness, or usefulness of any information, apparatus, product, or process disclosed, or represents that its use would not infringe privately owned rights. Reference herein to any specific commercial product, process, or service by trade name, trademark, manufacturer, or otherwise does not necessarily constitute or imply its endorsement, recommendation, or favoring by the United States Government or any agency thereof. The views and opinions of authors expressed herein do not necessarily state or reflect those of the United States Government or any agency thereof. 


\section{DISCLAIMER}

Portions of this document may be illegible in electronic image products. Images are produced from the best available original document. 
Reference to a company or product name does not imply approval or recommendation of the product by Union Carbide Corporation or the Department of Energy to the exclusion of others that may meet specifications.

Printed in the United States of America. Available from National Technical Information Service

U.S. Department of Commerce 5285 Port Royal Road, Springfield, Virginia 22161

Price: Printed Copy \$4.00; Microfiche \$3.00

This report was prepared as an account of work sponsored by an agency of the United States Government. Neither the United States Government nor any agency thereof, nor any of their employees, nor any of their contractors, subcontractors, or their employees, makes any warranty, express or implied, nor assumes any legal liability or responsibility for any third party's use or the results of such use of any information, apparatus, product or process disclosed in this report, nor represents that its use by such third party would not infringe privately owned rights. 


\title{
DEVELOPMENT OF AN AGING INTEGRATOR FOR URANIUM-0.75 WEIGHT PERCENT TITANIUM ALLOY PART AGING CONTROL
}

\author{
L. C. Howington \\ Instrumentation and Characterization Department \\ Y-12 Technical Division
}

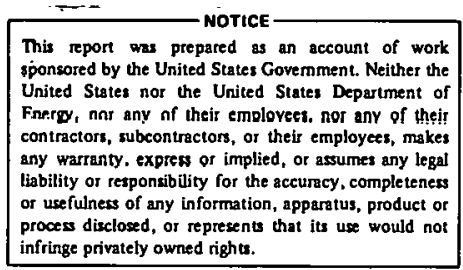

infringe privately owned rightu.

Oak Ridge Y-12 Plant

P. O. Box Y. Oak Ridge. Tennessee 37830

Prepared for the US Energy Research

and Development Administration

Under US Government Contract W.7405-eng=26 


\begin{abstract}
An instrumentation system (Aging Integrator) has been developed to provide more precise control of the heat-treatment process used on uranium- 0.75 weight percent titanium alloy material. The Aging Integrator calculates the integral of a predetermined aging function to control the aging period in the heat-treatment process. This control was employed to compensate for discrepancies caused by variations in heatup times, furnace-control fluctuations, and disagreement as to the temperature at which aging actually starts. Although the Aging Integrator hardware has been installed and satisfactorily tested on a production-area furnace, sufficient data to estimate a statistically sound aging integration function will not be available for approximately one year.
\end{abstract}


CONTENTS

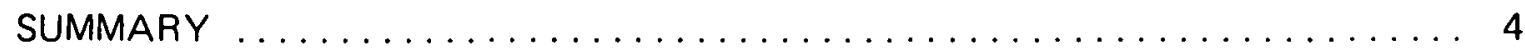

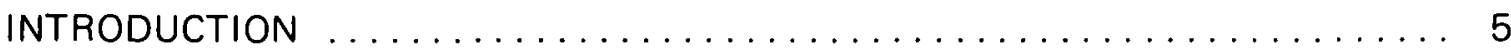

DEVELOPMENT OF AN AGING INTEGRATOR ................... 6

Theoretical Considerations ................................... 6

Hardware Specifications ................................. 10

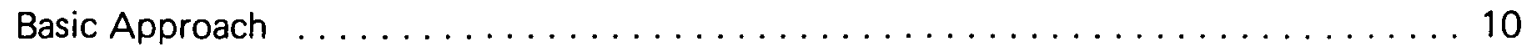

System Components . . . . . . . . . . . . . . . . . . . . . . . . . . . . . 11

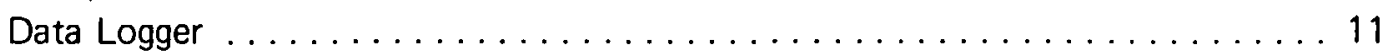

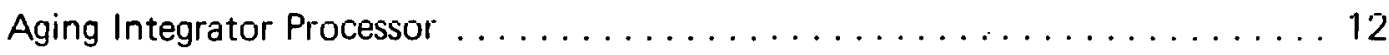

Control Panel . . . . . . . . . . . . . . . . . . . . . . . . . . . . . 12

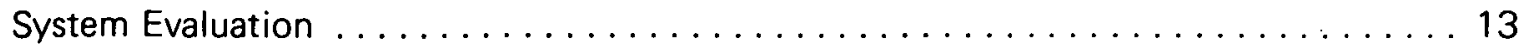

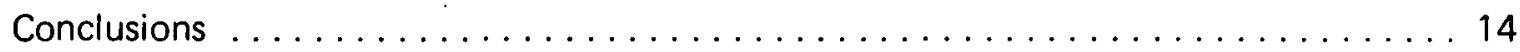

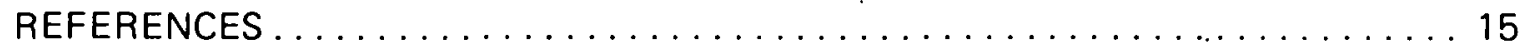

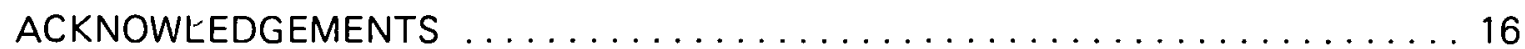




\section{SUMMARY}

To achieve the necessary yield strength (930 MPa) and ductility (18\% elongation) for uranium- 0.75 weight percent titanium (U-0.75 Ti) alloy, a more precise control of the material aging process was needed. To this end, an instrumentation system (Aging Integrator) was developed to provide a fixed integral of the aging-factor function with respect to time as a furnace-control parameter. The aging-factor function is derived empirically from plots of yield strength versus the aging period at a constant temperature. Use of the Aging Integrator should provide compensation for discrepancies caused by variations in heatup times, furnace-control fluctuations, and disagreement as to when the aging actually begins.

The hardware for implementing this control consists of a data logger to monitor the furance thermocouple and the aging period, and an aging integrator circuit to perform arithmetic computations and interface with the operator. Each time the data logger makes a temperature reading, the Aging Integrator hardwired arithmetic unit updates the integral and compares the update against a preset value. When the calculated integral equals the preset or ideal value, the heat-treatment cycle is terminated.

This system has been installed and satisfactorily tested on a production-area furnace. However, due to the lack of a sufficient data base from which to estimate an aging-factor function, any conclusive results depicting the effectiveness of the aging-integration procedure on U-0.75 Ti heat treatment will be delayed approximately one year. 


\section{INTRODUCTION}

The precise heat treatment of various alloys, such as uranium- 0.75 weight percent titanium (U-0.75 Ti), is of great concern at the Oak Ridge Y-12 Plant. (a) To achieve the necessary material properties, such as yield strength (930 MPa) and ductility (18\% elongation), an instrumentation system called an Aging Integrator was developed to control more precisely the aging period used in the U-0.75 Ti heat-treatment process. Although the process of aging integration has been implemented successfully in the heat treatment of aluminum alloys, ${ }^{1}$ this concept has not, as far as is known, been applied to the aging of uranium alloys.

The Aging Integrator controls aging time by integrating an aging-factor function which is derived empirically from plots of a specific material property, such as yield strength, versus aging time at several constant temperatures. Each time a furnace temperature reading is taken, the value of the integral is updated and compared against an ideal preset value. When the calculated integral equals the preset value, the aging process is terminated. This procedure should compensate for excursions from the normal constant aging temperature caused by furnace-control fluctuations, operator errors, or other discrepancies in the aging procedure.

(a) Operated by the Union Carbide Corporation's Nuclear Division for the Department of Energy. 


\section{DEVELOPMENT OF AN AGING INTEGRATOR}

\section{THEORETICAL CONSIDERATIONS}

To obtain a material with specific mechanical properties, a metallurgist noramlly either formulates or references experimental data similar to that shown in Figure 1.2 Here, a material property has been plotted as a function, $f(t, T)$, of the aging time, $t$, at a particular temperature, $T$. To heat treat the material to obtain the specific property, $P$, an extension would be made horizontally from the ordinate, $P$, to intersect one of the constant-temperature curves leg, $\left.T_{r}\right)$. The corresponding abscissa then reveals the time, $t_{r}$, required

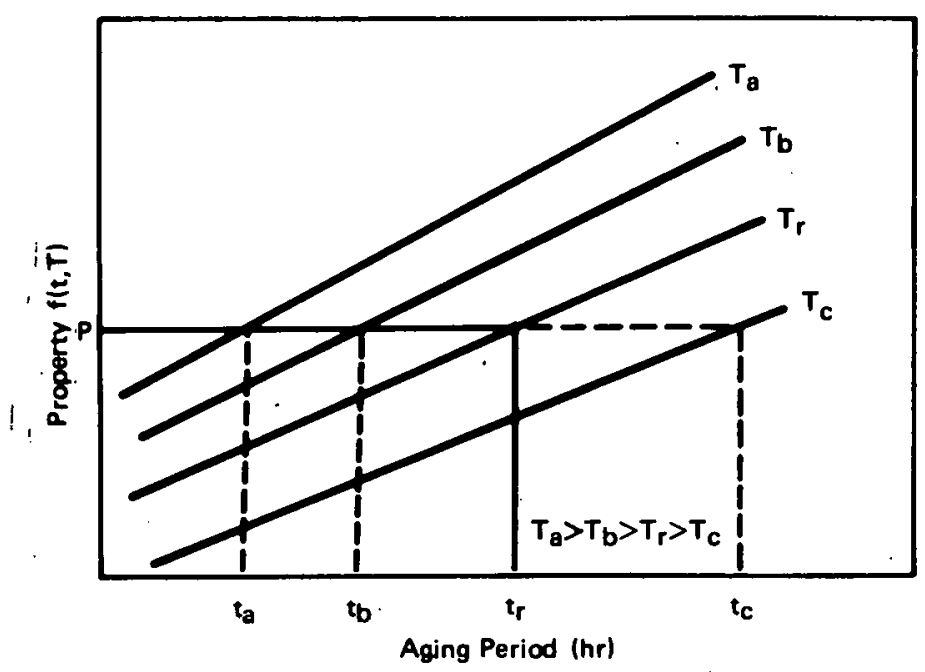

Figure 1. THEORETICAL PROPERTY, $f(t, T)$, AS A FUNCTION OF THE AGING TIME AND TEMPERATURE. to obtain the property, $P$, at temperature, $T_{r}$.

The same property, $P$, could also be obtained by using one of the other constant-temperature curves and obtaining a different aging period. This degree of freedom is usually eliminated, however, by the fact that several material properties (hence, plots) must be considered. Therefore, a single aging temperature/period combination is generally required to obtain optimum material properties.

Under ideal conditions (once the optimum temperature, $T_{r}$, and period, $t_{r}$, are selected), a plot of aging temperature versus aging time would appear as a step function (Figure 2) whose integral would be the area under the curve, or:

$$
\int_{0}^{t_{r}} \mathrm{~T}(\mathrm{t}) d t=t_{r} T_{r}(O \mathrm{C} \cdot h r) .
$$

However, discrepancies from this ideal curve are introduced by several factors which include: variations in heatup rates, furance-control fluctuations, and disagreement as to the temperature at which aging actually begins. In practice, then, a plot of temperature versus time (Figure 3) would exhibit temperature excursions. To express the integral of this curve in discrete form, the total time period is divided into discrete time divisions, $\Delta t$. The integral then takes the form:

$$
\int_{0}^{t} T(t) d t=\sum_{i=1}^{n} T_{i} \Delta t,
$$




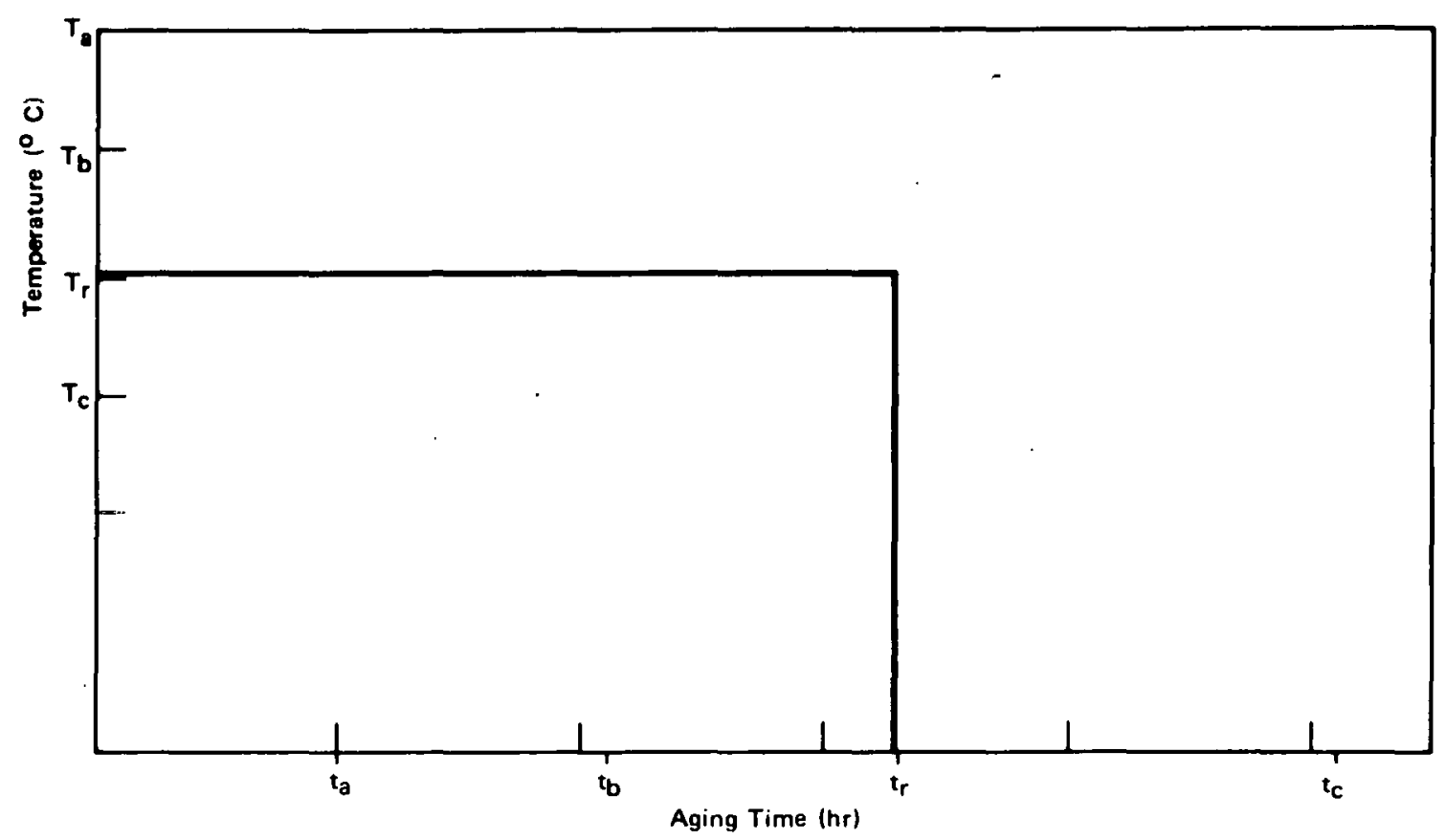

Figure 2. AGING TEMPERATURE AS A FUNCTION OF THE AGING TIME UNDER IDEAL CONDITIONS.

where $T_{i}$ represents the temperature amplitude sampled at time $i \Delta t$. Note that in the ideal case, $T_{j}$ is the constant $T_{r}$, making Equation 2 reduce to:

$$
\sum_{i=1}^{n} T_{i} \Delta t=T_{r} \sum_{i=1}^{n} \Delta t=T_{r} n \Delta t=t_{r} T_{r},
$$

which is the result given by Equation 1 .

In practical applications it would be desirable to compensate for the temperature excursions discussed previously. One method of compensation is the use of a weighting factor, or aging factor, w. For example. Figure 1 indicates that the same property, $P$, is obtained if the material is aged at the ideal reference temperature, $T_{r}$, for $t_{r}$ hours or at the lower temperature, $T_{C}$, for a longer period, $t_{C}$. The aging factor of temperature, $T_{C}$, relative to the reference would then be:

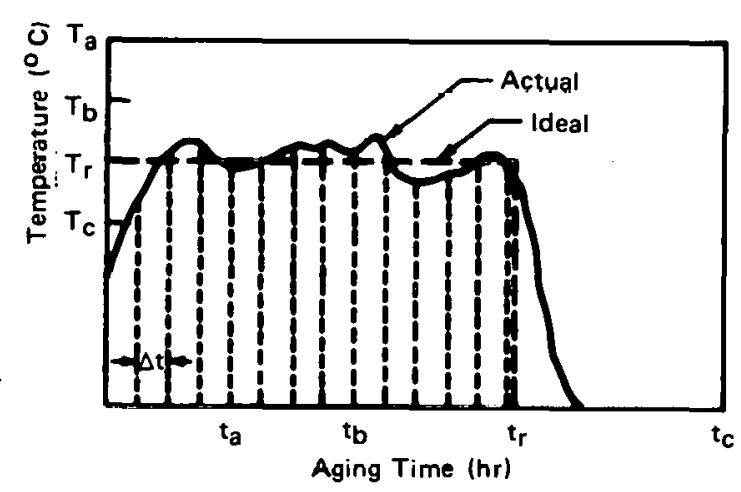

Figure 3. AGING TEMPERATURE AS A FUNCTION OF THE AGING TIME IN A REAL ENVIRONMENT.

$$
w=\frac{t_{r}}{t_{c}}
$$


Based on the previous argument, an aging factor function, $w(t, T)$, can be defined as:

$$
w(t, T)=\frac{t_{r}}{t(T)}
$$

where $t(T)$ represents the aging period required to produce the property, $P$, at temperature, $T$, instead of the ideal temperature, $T_{r}$. Note that $w(t, T)$ must be considered a function of both the aging period and aging temperature due to the $t(T)$ term. To obtain compensation for the temperature excursions that occur during an aging cycle, the aging-factor function is integrated with respect to time as follows:

$$
\int_{D}^{t} w(t, T) d t=\sum_{i=1}^{n} w\left(t, T_{i}\right) \Delta t .
$$

Aging is then terminated when this integral equals the ideal reference period, $t_{r}$, such that:

$$
\sum_{i=1}^{n} w\left(t, T_{i}\right) i \Delta t=t_{r} .
$$

For example, consider the trivial case where a constant aging temperature, $T_{C}$, is used instead of $T_{r}$. The period at which aging will terminate can be derived from Equation 7 as:

$$
\begin{aligned}
& \sum_{i=1}^{n} w\left(t, T_{C}\right) \Delta t=t_{r}, \text { or } \\
& \sum_{i=1}^{n} \frac{t_{r}}{t\left(T_{C}\right)} \Delta t=t_{r}, \text { or } \\
& \frac{t_{r}}{t_{c}} \sum_{i=1}^{n} \Delta t=t_{r}, \text { or } \\
& \frac{t_{r}}{t_{c}} n \Delta t=t_{r}, \text { or } \\
& n \Delta t=t_{c} .
\end{aligned}
$$

Note that $n \Delta t$ is indeed the aging period predicted by Figure 1 .

Now considering the nontrivial case, the integral of $w(t, T)$ would be as follows: 


$$
\sum_{i=1}^{n} w\left(t, T_{i}\right) \Delta t=\frac{t_{r}}{t\left(T_{1}\right)} \Delta t+\frac{t_{r}}{t\left(T_{2}\right)} \Delta t+\cdots+\frac{t_{r}}{t\left(T_{n}\right)} \Delta t
$$

where $n$ would be the unknown. From this expression, each time the furnace temperature is sampled to obtain $T_{i}$, the corresponding aging period, $t_{i}$, must be determined to normalize the ideal aging period, $t_{r}$. The product of this aging factor is multiplied by the sampling period, $\Delta t$, and the sum is updated to be compared with the ideal aging period, $t_{r}$. Aging is terminated when the ideal aging period is reached. Aging integration, thus, varies the aging period to account for temperature fluctuations.

An alternate (and, perhaps, more traditional) way of describing the heat-treatment process is by the integral of aging temperature with respect to time during the aging period, as was expressed in Equation 3. The aging-factor-function concept can also be incorporated into this expression. In this case, the preset constant will not be the ideal aging period, $t_{r}$, but the ideal aging integral value, $t_{r} T_{r}$. The aging-factor function, itself, must be altered for this application.

The alternate aging-factor function can be designated as $w^{\prime}(t, T)$. The desired condition for terminating the aging cycle can then be expressed as:

$$
\sum_{i=1}^{n} w^{\prime}\left(t, T_{i}\right) T_{i} \Delta t=t_{r} T_{r}
$$

Using Equation 7 and multiplying each term in the summation by $T_{i} / T_{i}$, while multiplying both sides of the equation by $T_{r}$ yields:

$$
\begin{aligned}
& T_{r} \sum_{i=1}^{n} w(t, T) \frac{T_{i}}{T_{i}} \Delta t=t_{r} T_{r}, \text { or } \\
& \sum_{i=1}^{n} w(t, T) \frac{T_{r}}{T_{i}} \dot{T}_{i} \Delta t=t_{r} T_{r},
\end{aligned}
$$

which is the same form. as Equation 10. Comparing Equations 10 and 12, the alternate aging-factor function can be written as:

$$
w^{\prime}(t, T)=\frac{T_{r}}{T} w(t, T)=\frac{T_{r}}{T} \frac{t_{r}}{t(T)} .
$$

This form simply allows the ideal aging integral to be used as a preset value expressed in units of ${ }^{\circ} \mathrm{C} \cdot \mathrm{hr}$ instead of the ideal aging period which would be expressed in units of time (eg, hours). 
At this point, limitations concerning application of the aging integration method to $\mathrm{U}-0.75 \mathrm{Ti}$ heat treatment should be mentioned. The fact that compensation can be made for temperature excursions does not imply that the aging temperature is unbounded. Although increased aging temperature increases the yield strength of U-0.75 Ti, percent elongation is decreased. The interaction of these two properties yields an optimum aging temperature of approximately $370^{\circ} \mathrm{C}$, which should probably vary no more than $\pm 10^{\circ} \mathrm{C}$ for any extended period of time. Aging integration, then, is intended to correct for short-term temperature fluctuations about the ideal aging temperature. Furthermore, the absolute maximum upper

limit has been projected as $400^{\circ} C^{2}$ At present, $t_{r}$ is predicted as 7 to 8 hours. Since adequate data for formulating the aging-factor function and aging parameters has not been processed at this time, these figures are tentative.

\section{HARDWARE SPECIFICATIONS}

Basic requirements for the aging-integration hardware (Aging Integrator) are specified as follows:

1. Measure the furnace (part) temperature with a resolution of $10^{\circ} \mathrm{C}$.

2. Sample the furnace temperature and update the integral every 36 seconds $(\Delta t=0.01 \mathrm{hr}$ ).

3. Provide an adjustable base-temperature setpoint below which no. integration takes place.

4. Provide the capability to integrate, using either of the aging-factor functions $[w(t, T)$ or $\left.w^{\prime}(t, T)\right]$.

5. Provide an adjustable setpoint to specify either the ideal aging period, $t_{r}$, or integral value, $t_{r} T_{r}$.

6. Provide hardcopy printout of temperature measurements, time, and current integral value with an adjustable printout rate.

7. Provide an indicator and the capability to turn the furnace off when the preset integral value is reached.

8. Provide the capability of using a variety of thermocouple types.

\section{BASIC APPROACH}

After surveying the instruments that are currently available, a data logger interfaced to a custom-designed integration logic was chosen as the approach to use in building the Aging Integrator. The block diagram in Figure 4 illustrates the major components of the Aging Integrator. The data logger and aging integrator processor (AIP) act in a master/slave relationship. The data logger acts as the master device in making the thermocouple measurements and controlling the sample rate; the AIP acts as a slave device in that it is 
activated each time it receives the digital temperature data. When activated, the AIP updates the integral and control-panel display, outputs the new integral value to the data logger, and turns the furance off, if necessary. Furnace cutoff can be implemented through either the existing controller or a relay complex in parallel to the existing controller.

\section{SYSTEM COMPONENTS}

Each of the three major components: the data logger, the AIP, and the control panel, will now be discussed in greater detail.

\section{Data Logger}

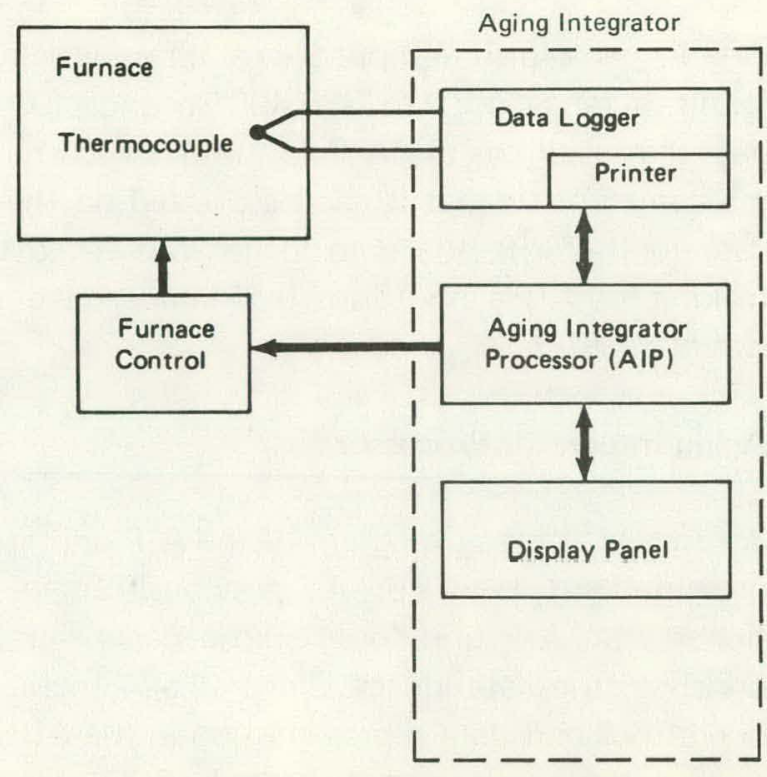

Figure 4. PRINCIPAL COMPONENTS OF THE AGING INTEGRATOR.

The Fluke Model 2240A data logger (Figure 5), chosen for this project, satisfies several of the design specifications. ${ }^{3}$ It provides ice-point compensation and normalization with $10 \mathrm{C}$ resolution for several thermocouple types: Chromel/Alumel (Type K), platinum/13\% rhodium (Type R), platinum/10\% rhodium (Type S), and tungsten/tungsten-26\% rhenium (Type G). A 16-column digital printer built into the data logger provides a printout of the date, time of day, identification number, digital input data, and temperature readings. The

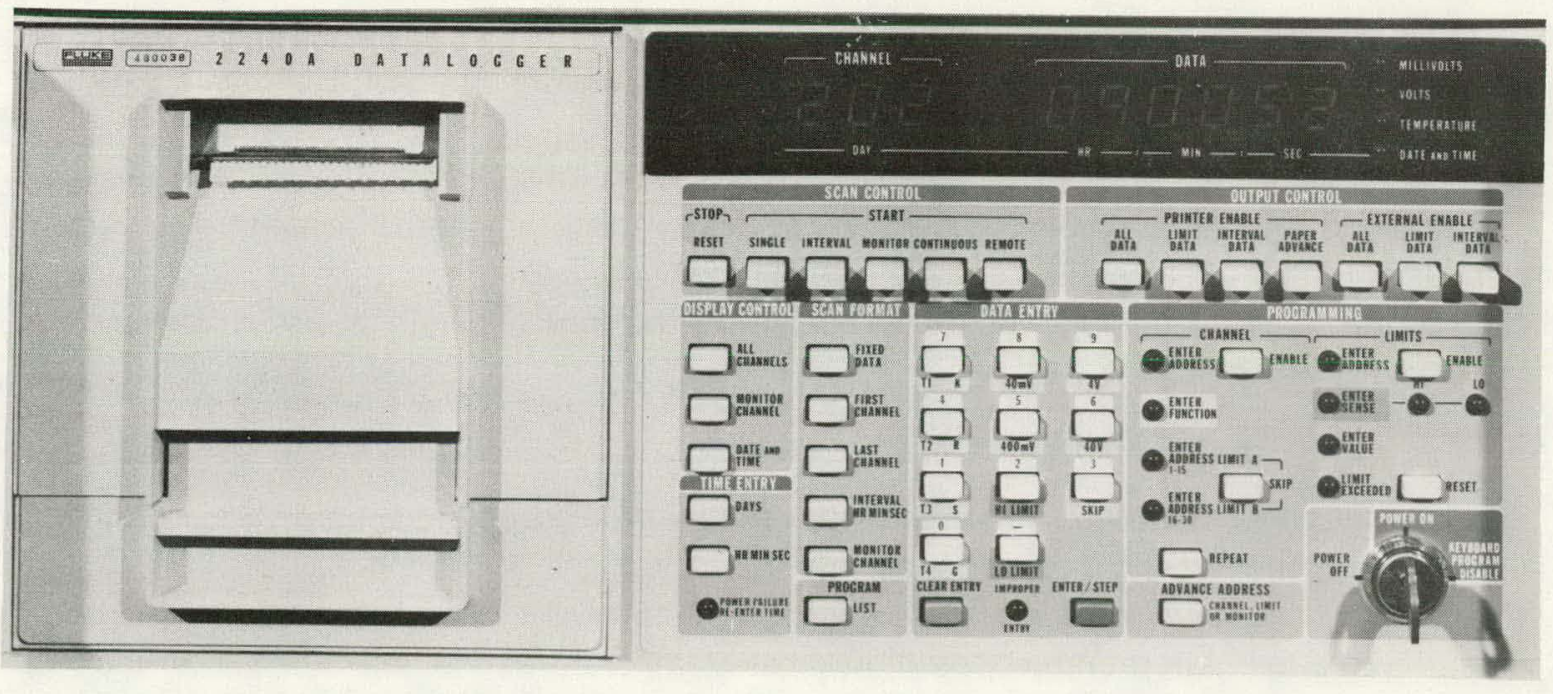

Figure 5. FLUKE MODEL 2240A DATA I OGGER USED IN THE AGING INTEGRATOR. 
data logger is also equipped with an externally adjustable timer to control the sample rate within a range of 1 to 356,400 seconds $(99 \mathrm{hr}$ ). A digital-input option supplied with the data logger allows the AIP to input the current value of the integral after each temperature measurement so that it can be printed on the data logger's printer. To output temperature data to the AIP, the data logger was fitted with a paper-tape-punch interface option. By making the AIP's input look like a paper-tape punch, an efficient means of data transmission was effected.

\section{Aging Integrator Processor}

A functional block diagram of the AIP unit is presented in Figure 6. As previously mentioned, the AIP unit looks like a paper-tape punch to the data logger. Since all arithmetic operations and data representation in the AIP involve the binary-coded-decimal (BCD) format, the character-serial, bit-paralleltransmission-mode characteristic of the paper-tape-punch interface simplifies the input decoding required in the AIP. At the end of a sample interval $\left(\Delta t_{j}\right)$, the AIP receives a string of information from the data logger identical to what is printed on the logger's printer. Ignoring all information except the first temperature reading $\left(T_{j}\right)$, this temperature value is compared by the control

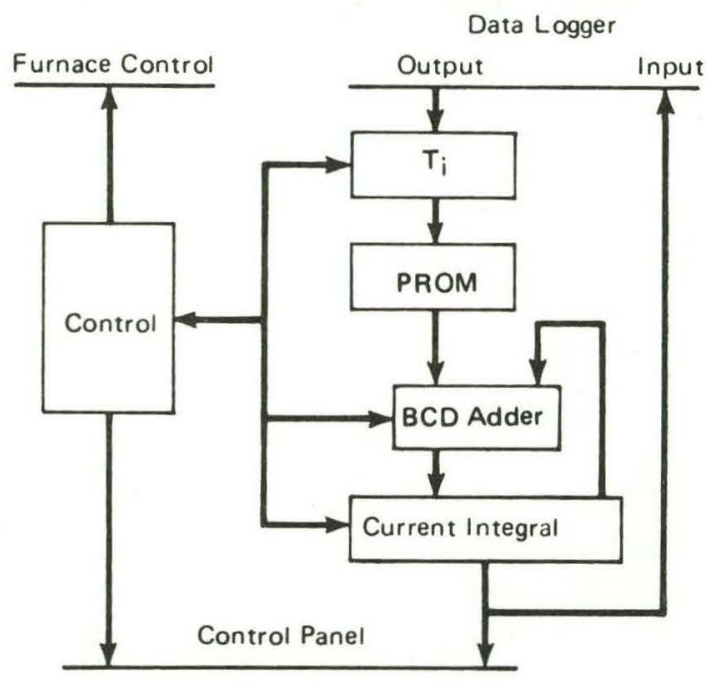

Figure 6. FUNCTIONAL ARRANGEMENT OF THE AGING INTEGRATOR PROCESSOR. unit to the base-temperature setting on the control panel. If $T_{i}$ is less than the base temperature, no further processing is done; if, however, $T_{j}$ is greater than the base temperature, the AIP continues processing by using the value of $T_{i}$ as an address to a programmable read only memory (PROM). This PROM contains the precomputed aging factor term, [either $w\left(t, T_{j}\right)$ or $w^{\prime}\left(t, T_{j}\right) T_{j}$, depending on the method being used], which is then added to the current integral value using the BCD adder. The updated integral is then compared to the setpoint on the control panel to determine if aging is complete. If aging is complete, the furance is cut off. The updated integral is then clocked into the data logger to be printed and onto the control panel for visual display.

\section{Control Panel}

The control panel (Figure 7) physically consists of three groups of thumbwheel switches, a light-emitting-diode (LED) numeric display, a Sonalert, and various indicators. The PRINT INTERVAL thumbwheels are used to set the time interval at which the data logger prints data; the BASE TEMP thumbwheels allow a base temperature to be selected below which no integration occurs; the INTEGRAL thumbwheels are used to select the reference-integral value, while the LED numeric display provides the current value of the integral. A Sonalert is used to attract the operator's attention when aging is complete (FURNACE LED is off) or 
an open thermocouple has been detected (ALARM LED is on). The START/RESET button allows the AIP logic circuitry to be cleared in preparation for an aging run.

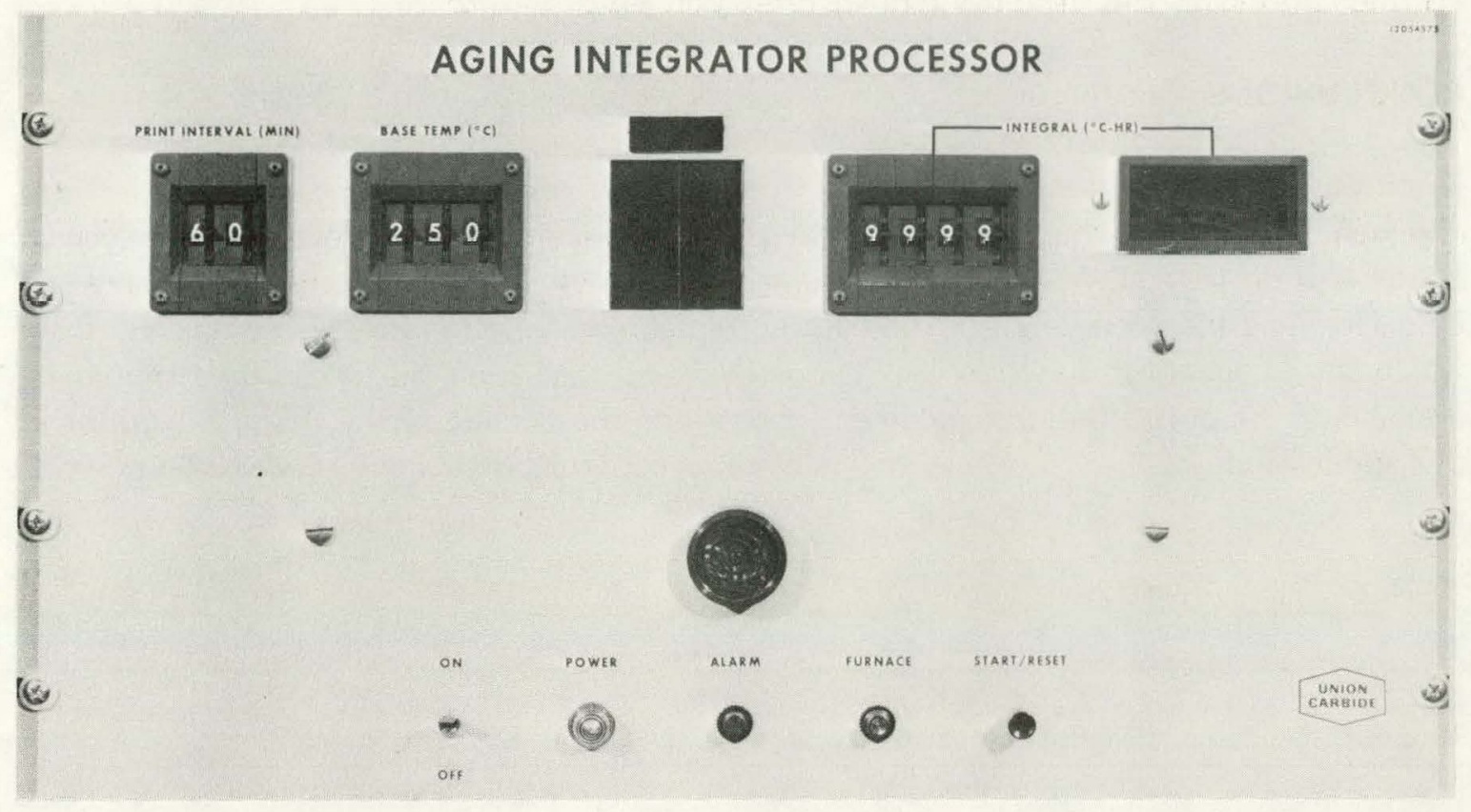

Figure 7. CONTROL PANEL OF THE AGING INTEGRATOR PROCESSOR.

174479

\section{SYSTEM EVALUATION}

The Aging Integrator was first evaluated in the laboratory to determine that the AIP unit was functioning properly. For evaluation purposes, the PROM was programmed such that each memory location contained its own address. The sampled temperature measurement, $\mathrm{T}_{\mathrm{i}}$, then addressed and selected a value that was equal to itself. This procedure resulted in the Aging Integrator simply calculating the integral of temperature with respect to time. To determine whether or not the AIP was performing properly, the temperature readings from the data logger's printout were summed and compared with the value produced by the AIP. Using this procedure, the AIP was debugged and determined to be operating satisfactorily after several 24-hour runs at room temperature. To test the system over an extended period, the unit was operated continuously for two weeks. No problems were encountered during this period.

Next, the Aging Integrator was installed on an aging furnace in the production area of the Plant. Because of an insufficient data base, a credible aging-factor function could not be determined. For this reason, no attempt was made to implement the control function of the integrator. Instead, it was allowed to operate as a monitoring device and annunciate when integration was complete. Only one aging run has been made since the system was installed. During the furnace run, the data-logger output was checked by comparison with the output of a Doric digital thermocouple monitor connected to a furnace thermocouple installed next 
to the data logger's thermocouple. The two devices agreed within $10 \mathrm{C}$, thus indicating satisfactory operation. The operational integrity of the Aging Integrator was further affirmed during a series of solution quench tests on a nearby furnace.

\section{CONCLUSIONS}

Based on evaluations thus far, the Aging Integrator performs the function for which it was designed. However, at this point, no conclusions can be drawn concerning the effectiveness of the AIP on the U-0.75 Ti heat-treatment process. Metallurgy Department personnel will be performing the necessary test runs during the coming year to establish a data bank from which an aging-factor function can be derived. At that time, sufficient data should be available to support a definite statement concerning the benefit of the Aging Integrator in this application. 


\section{REFERENCES}

1. Alcoa 420 Aging Integrator Process, Report 20; Alcoa Technology Marketing Division, Pittsburgh, Pennsylvania.

2. Jessen, N. C., Jr; Personal Conversation; January 10, 1977.

3. Fluke Model 2240A Instruction Manual; John Fluke Manufacturing Company (1977). 


\section{ACKNOWLEDGEMENTS}

The author would like to express his appreciation to several members of the $\mathrm{Y}-12$ Development Division for their significant contributions: to W. H. Dodson and N. C. Jessen, Jr of the Metallurgy Department for providing the basic concepts and making the project possible; to P.S. Lewis, Jr and H. L. Wigginton of the Metallurgy Department for help in installing and evaluating the Aging Integrator; to R. R. Burleson of the Fabrication Systems Department for aid in using the PROM programming system, and to P. C. Turner of the Instrumentation and Characterization Department for assistance in specifying a data logger. 


\section{Distribution}

Department of Energy - Albuquerque

Vespe, V. C.

Department of Energy - Oak Ridge

Hickman, H. D.

Leed, R. E.

Zachry, D. S., Jr

\section{Lawrence Livermore Laboratory}

Nelsoni, W. E.

Technical Information Library

Los Alamos Scientific Laboratory

Hoyt, H. C.

Library Services

Oak Ridge Gaseous Diffusion Plant

Stief, S. S.

Wilcox, W. J., Jr

Oak Ridge National Laboratory

Weir, J. R., Jr

Oak Ridge Y.12 Plant

Alvey, H. E.

Armstrong, R. C.

Bernander, N. K.

Bostock, D. J.

Briscoe, O.W.

Burditt, R. B.

Dodson, W. H

Duggan. H. G.

Foulk, D. L.

Fraser, R. J.

Howington, L. C. (6)

Jackson, V. C.

Jessen, N. C.

Jones, F. W.

Kahl. K. G.

Keith, A.

Kite, H. T.

Marrow, G. B.

Martin, W. R./Googin, J. M.

Mason, D. L./Schreyer, J. M.
McLendon, J. D.

Mills, J. M., Jr

Oliphant, G.W.

Phillips, L. R.

Rhew, J. E.

Smith, R. D.

Smith, W. E.

Stephens, A. E.

Stoner, H. H.

Tewes, W. E.

Thompson, W. H., Jr

White, J. C.

Whitson, W. K.

Williams, R. D.

$Y-12$ Central Files (master copy)

$Y-12$ Central Files (route copy)

$Y-12$ Central Files ( $Y$-12RC)

$Y-12$ Central Files (5)

\section{Paducah Gaseous Diffusion Plant}

Bewley, H. D.

Sandia - Albuquerque

Mail Service Section

\section{Sandia - Livermore}

Technical Library

Union Carbide Corporation - New York

Chambers, W. E.

Winters, $C$.

University of Tennessee -

College of Engineering

Stansbury, E. E. 